\title{
Mediate evaluation of replicating a Training Program in Nonverbal Communication in Gerontology
}

\author{
Avaliação mediata na replicação do programa de capacitação \\ em comunicação não verbal em gerontologia \\ Evaluación mediata en la replicación del programa de capacitación \\ en comunicación no verbal en gerontología
}

Teresa Cristina Gioia Schimidt ${ }^{1}$, Yeda Aparecida de Oliveira Duarte ${ }^{2}$, Maria Julia Paes da Silva ${ }^{3}$

${ }^{1}$ Professor, Universidade Nove de Julho, São Paulo, SP, Brazil.

${ }^{2}$ Associate Professor, Faculty of Nursing, Universidade de São Paulo, São Paulo, SP, Brazil.

${ }^{3}$ Research and study group coordinator of communication in Nursing for CNPq, São Paulo, SP, Brazil.

\section{ABSTRACT}

Objective: Replicating the training program in non-verbal communication based on the theoretical framework of interpersonal communication; non-verbal coding, valuing the aging aspects in the perspective of active aging, checking its current relevance through the content assimilation index after 90 days (mediate) of its application. Method: A descriptive and exploratory field study was conducted in three hospitals under direct administration of the state of São Paulo that caters exclusively to Unified Health System (SUS) patients. The training lasted 12 hours divided in three meetings, applied to 102 health professionals. Results: Revealed very satisfactory and satisfactory mediate content assimilation index in $82.9 \%$. Conclusion: The program replication proved to be relevant and updated the setting of hospital services, while remaining efficient for healthcare professionals.

\section{DESCRIPTORS}

Nonverbal Communication; Aged; Aging; Health Education; Geriatric Nursing.
Correspondence Addressed to: Teresa Cristina Gioia Schimidt

Av. Dr Enéas de Carvalho Aguiar, 188 - Sala 409 - Cerqueira Cesar

CEP 05403-000 - São Paulo, SP, Brazil

tschimidt@saude.sp.gov.br 


\section{INTRODUCTION}

Aging is a process of physical, mental, cognitive and social losses, which brings vulnerabilities. These are differentiated by gender, age, social group, race, geographic regions, etc. The moment - age at which the losses start - should also be considered. Therefore, it is considered that public policy can play a crucial role in reducing their impact on the individual and society ${ }^{(1)}$.

In 2013, the Government of São Paulo State created the State Program Sao Paulo Friend of the Elderly, with the intention of contributing towards a more inclusive society for all ages and to be attentive to the existing context. Among the objectives included were to appreciate the elderly, ensure the defense of their rights, implement a support network for direct assistance to the elderly, provide support for families and also encourage better training ${ }^{(2)}$.

The theoretical framework of the program is based on the political framework for Active Ageing recommended by the World Health Organization that advocates overcoming a naturalized view of the relationship between aging and inactivity and proposes that there is a focused look at human rights; that dignity, security, full participation and independence of the elderly are present and adjusted to their needs ${ }^{(3)}$.

Appropriate geriatric care values the context in which the older person lives in, which support networks are available to them and how they integrate, comprised of several factors: the elderly, the family, the caregiver (if there is one), the community and the health care teams. Everyone should act in an interrelated manner and with focus on the integrated care, as one that respects the individuality, autonomy and maintains or maximizes the independence of the elderly ${ }^{(4)}$.

Managing care not only for but with the elderly requires technical knowledge, healthcare knowledge, management expertise, ability in problem solving techniques and communication skills from the health professional. These are comprised of a multitude of nuances that deserve and need to be studied in order to be consciously applied in daily life, therefore resulting in effective health care also consistent with the expression of affection ${ }^{(5)}$.

Elderly care may happen at different levels; here the focus is on the hospital, a place where older person's life, limits and weaknesses are often exposed. Unfortunately, hospital care has not always achieved an appropriate combination of technical and practical knowledge, that which has been producing care short of the expectations and needs of the elderly, causing concern, frustration, and worsening their health condition ${ }^{(6)}$.

Furthermore, sometimes when the elderly are assisted in hospitals, they do not receive the proper medical or psychosocial approach, causing the assistance to be of little use, unwelcoming and superficial ${ }^{(5-6)}$.

The training proposed in this project was applied and validated in 2009 by a doctorate at the time, implemented in hospitals in São Paulo. The results showed the main strengths of the training program as the quality of the content approached in meetings on self-knowledge and teamwork; the aging process; myths and stereotypes about elderly; nonverbal dimensions; the quality of teaching resources used and the proper organization of meetings.

Participants were able to comprehend that although aging manifests itself though a decline in the functions of the various organs (which varies not only from one another but also from people to people of the same age), the elderly cannot only be reduced to this stage of deterioration. It was identified that participant's vision regarding the elderly interferes in their manner of relating to them. Participants admitted that, sometimes, the prejudice against the elderly and the aging process is latent and is part of everyday reality; before training little thought was put into the issue, but after training it can be better addressed.

Studying aging and non-verbal communication matters have led participants to deal with concepts that were before unknown. Through participant's testimonies, their need for further clarification of issues relating to aspects of gerontology became clear, since the elderly will always represent a relevant part in health services.

It is believed that by using the communication resources, health professionals will be able to readily and quickly recognize individual needs of the elderly and include them in the planning, execution and evaluation of the assistance provided, guaranteeing a real opportunity for the elderly to exercise their autonomy and/or the maintenance and expansion of their functional and cognitive ability, as these are constituted by their own rights.

The objective of this study was to re-apply the training program about nonverbal communication based on the theoretical framework of interpersonal communication; non-verbal coding, valuing the aging aspects of the active aging perspective, measuring the effectiveness through the content assimilation index of the program, 90 days after its application.

\section{METHOD}

Descriptive and exploratory field work conducted in three large and medium-sized hospitals exclusively for public (SUS) service under the direct administration of the State, belonging to the Regional Network of Health Care in the State of São Paulo (RRAS 06 - Capital), having the elderly as clients in their scenario. Nursing and also undergraduates, graduate students, residents and / or health professionals were invited to participate in the technical study, provided they were necessarily linked to the institution, either for employment or by education; they had to show interest and availability to attend the scheduled days of training; assume commitment to be present at all meetings, and spontaneously agree to participate in the study and sign an Informed Consent Statement. The research obeyed all the rules established by the National Health Council Resolution 466/2012, with opinion adopted under number: 351.492/2013.

The training program complied with a pedagogical matrix and lasted 12 hours over three sessions of four hours each and occurred during business hours of weekdays. 
Program evaluation was performed in two stages: immediate and mediate. The immediate was done through checking the content assimilation at the end of each of the three meetings; the mediate 90 days after completion of training (last meeting). When returning to the institutions, a 12 minute excerpt of the movie The Bucket List (Director: Rob Reiner; Distributor: Warner Bros; Year: 2008) was shown. An instrument was applied in which the participant should choose and describe a movie scene to illustrate each of the six non-verbal dimensions studied during training (paralanguage, haptics, proxemics, kinesics, physical characteristics and environmental factors) and to identify which one or more of the four non-verbal functions was/were correlated.

The participant was able to settle in, watch the movie excerpt, get directions and a printed record, watch the movie excerpt again and take notes. This step had a total duration of 40 minutes.

Data relating to mediate evaluation was based on the following steps: reading the answers; checking the answers based on an answer key; establishing criteria for determining satisfaction (very satisfactory, satisfactory and unsatisfactory) and tabulation of results.

\section{RESULTS}

The 102 health professionals who participated in the training were divided into three groups $(A=38, B=41$ and $\mathrm{C}=23$ ); however, only $70 \%(65.6 \%)$ showed up to the mediate evaluation. Group distribution was $\mathrm{A}=25(65.8 \%)$, $\mathrm{B}=30(73.2 \%)$ and $\mathrm{C}=15(65.2 \%)$.

Of these, 78.6\% (55) had higher education, 21.4\% (15) had a technical level. In relation to gender and age, $91.4 \%$ (64) were women with an average age of 45.4 years, median of 47.5 years and $8.6 \%$ (6) were men with an average of 41.0 and median of 42.7 years of age.

In analyzing participants with higher education, 49.1\% (27) were nurses, $20.0 \%$ (11) psychologists, $14.5 \%$ (8) social workers, $7.3 \%$ (4) physical therapists, 3.6\% (2) speech therapists, and $5.5 \%$ (3) from other areas. Participants with technical level were exclusively composed of nursing technicians.

The film excerpt chosen had 201 different moments that could be used as opportunities for the recognition of nonverbal communication functions, distributed as follows: $67.1 \%$ demonstrating feelings; $23.4 \%$ complementing, ratifying and/or reinforcing verbal communication; $8.0 \%$ replacing verbal communication and $1.5 \%$ contradicting verbal communication. It was clarified that in the same way that a function can have one or more non-verbal dimension, the same scene sequence could express more than one function.

There was no intention in creating moments or scenes in which functions were distributed proportionately as this would not portray the reality of everyday life, and there would be a greater importance between functions. Depending on the situational context, one would assume a more prominent role than the other.

Data revealed 544 scenes cited, in which one of the functions was present. These functions were identified as: $59.4 \%$ (323) - functions demonstrating feelings; $22.4 \%$
(122) - complementing, ratifying and/or reinforcing verbal communication; $15.1 \%$ (82) - replacing verbal communication, and 3.1\% (17) - contradicting verbal communication.

Results showed that participants of the mediate assessment identified nonverbal functions: $100.0 \%$ (70) functions demonstrating feelings; $87.8 \%$ (65) complementing, ratifying and/or reinforcing verbal communication; $81.4 \%$ (57) replacing verbal communication and $21.4 \%$ (15) contradicting verbal communication.

Table 1 - Relative distribution and percentage of participant's mediate evaluation into three groups (A, B and C) as identifying features of non-verbal communication - São Paulo, January to May 2014

\begin{tabular}{|c|c|c|c|c|}
\hline Non-verbal Function & A & B & C & Total \\
\hline \multicolumn{5}{|l|}{ Demonstrating feelings } \\
\hline $\mathrm{N}^{\circ}$ of people who identified it & $\begin{array}{c}25 \\
(100.0)\end{array}$ & $\begin{array}{c}30 \\
(100.0)\end{array}$ & $\begin{array}{c}15 \\
(100.0)\end{array}$ & $\begin{array}{c}70 \\
(\mathbf{1 0 0 . 0})\end{array}$ \\
\hline $\mathrm{N}^{\circ}$ of moments & $\begin{array}{c}111 \\
{[34.4]}\end{array}$ & $\begin{array}{c}139 \\
{[43.0]}\end{array}$ & $\begin{array}{c}73 \\
{[22.6]}\end{array}$ & $\begin{array}{c}323 \\
{[100.0]}\end{array}$ \\
\hline \multicolumn{5}{|c|}{ Complementing, ratifying and/or reinforcing verbal communication } \\
\hline $\mathrm{N}^{\circ}$ of people who identified it & $\begin{array}{c}22 \\
(88.0)\end{array}$ & $\begin{array}{c}28 \\
(93.3)\end{array}$ & $\begin{array}{c}15 \\
(100.0)\end{array}$ & $\begin{array}{c}65 \\
(87.8)\end{array}$ \\
\hline $\mathrm{N}^{\circ}$ of moments & $\begin{array}{c}41 \\
{[33.6]}\end{array}$ & $\begin{array}{c}39 \\
{[32.0]}\end{array}$ & $\begin{array}{c}42 \\
{[34.4]}\end{array}$ & $\begin{array}{c}122 \\
{[100.0]}\end{array}$ \\
\hline \multicolumn{5}{|c|}{ Replacing verbal communication } \\
\hline $\mathrm{N}^{\circ}$ of people who identified it & $\begin{array}{c}17 \\
(68.0)\end{array}$ & $\begin{array}{c}28 \\
(60.0)\end{array}$ & $\begin{array}{c}12 \\
(80.8)\end{array}$ & $\begin{array}{c}57 \\
(81.4)\end{array}$ \\
\hline $\mathrm{N}^{\circ}$ of moments & $\begin{array}{c}39 \\
{[47.5]}\end{array}$ & $\begin{array}{c}29 \\
{[35.4]}\end{array}$ & $\begin{array}{c}14 \\
{[17.1]}\end{array}$ & $\begin{array}{c}82 \\
{[100.0]}\end{array}$ \\
\hline \multicolumn{5}{|c|}{ Contradicting verbal communication } \\
\hline $\mathrm{N}^{\circ}$ of people who identified it & $\begin{array}{c}05 \\
(20.0)\end{array}$ & $\begin{array}{c}07 \\
(23.3)\end{array}$ & $\begin{array}{c}03 \\
(20.0)\end{array}$ & $\begin{array}{c}15 \\
(21.4)\end{array}$ \\
\hline $\mathrm{N}^{\circ}$ of moments & $\begin{array}{c}05 \\
{[29.4]}\end{array}$ & $\begin{array}{c}07 \\
{[41.2]}\end{array}$ & $\begin{array}{c}05 \\
{[29.4]}\end{array}$ & $\begin{array}{c}17 \\
{[100.0]}\end{array}$ \\
\hline
\end{tabular}

Notes:

$\mathrm{n}(\%)$ - percentage calculated on the number of people who attended the mediate evaluation.

$\mathrm{n}[\%]$ - percentage calculated on the total number of times a function was recognized.

For the total sum of recognized times when the four functions of nonverbal communication were observed in all three groups, the quantitative result was the following in descending order: B (214 - 39.4\%), A (196 - 36.0\%) and C (134-24.6\%).

In applying the proportionality test (number of correctly identified moments/participant), the descending order obtained was: C (8.9); A (7.8) and B (7.1). It can be said that in numerical and proportional terms, all groups recognized at least one moment where one or more functions were observed.

Regarding non-verbal dimensions and recognition of non-verbal functions of communication, the results statistically showed that Kinesics was most frequently recognized replacing verbal function; paralanguage complementing, ratifying and/or reinforcing verbal function, and Haptics, Environmental factors, Proxemics and Physical characteristics were more frequently identified in functions showing feelings. 
Table 2 - Participants' distribution and relative percentage in mediate evaluation, according to non-verbal functions and dimensions - São Paulo, January to May 2014.

\begin{tabular}{|c|c|c|c|c|c|c|c|}
\hline \multirow[b]{2}{*}{$\begin{array}{l}\text { Non-Verbal Functions } \\
\text { Of Communication }\end{array}$} & \multicolumn{6}{|c|}{ Non-verbal dimension } & \multirow[b]{2}{*}{ Total } \\
\hline & Kinesics & Paralanguage & Haptics & $\begin{array}{l}\text { Environmental } \\
\text { factors }\end{array}$ & Proxemics & $\begin{array}{c}\text { Physical } \\
\text { characteristics }\end{array}$ & \\
\hline Demonstrating feelings & $\begin{array}{c}50 \\
42.4 \%\end{array}$ & $\begin{array}{c}62 \\
53.5 \%\end{array}$ & $\begin{array}{c}63 \\
68.5 \%\end{array}$ & $\begin{array}{c}41 \\
54.7 \%\end{array}$ & $\begin{array}{c}55 \\
75.3 \%\end{array}$ & $\begin{array}{c}52 \\
74.2 \%\end{array}$ & $\begin{array}{c}323 \\
59.4 \%\end{array}$ \\
\hline $\begin{array}{l}\text { Complementing, ratifying } \\
\text { and/or reinforcing verbal } \\
\text { communication }\end{array}$ & $\begin{array}{c}46 \\
39.0 \%\end{array}$ & $\begin{array}{c}26 \\
22.4 \%\end{array}$ & $\begin{array}{c}24 \\
26.1 \%\end{array}$ & $\begin{array}{c}18 \\
24.0 \%\end{array}$ & $\begin{array}{c}08 \\
11.0 \%\end{array}$ & $\begin{array}{l}- \\
-\end{array}$ & $\begin{array}{c}122 \\
22.4 \%\end{array}$ \\
\hline $\begin{array}{l}\text { Replacing verbal } \\
\text { communication }\end{array}$ & $\begin{array}{c}13 \\
11.0 \%\end{array}$ & $\begin{array}{c}21 \\
18.1 \%\end{array}$ & $\begin{array}{c}05 \\
5.4 \%\end{array}$ & $\begin{array}{c}16 \\
21.3 \%\end{array}$ & $\begin{array}{c}09 \\
12.3 \%\end{array}$ & $\begin{array}{c}18 \\
25.7 \%\end{array}$ & $\begin{array}{c}82 \\
15.1 \%\end{array}$ \\
\hline $\begin{array}{l}\text { Contradicting verbal } \\
\text { communication }\end{array}$ & $\begin{array}{c}09 \\
7.6 \%\end{array}$ & $\begin{array}{c}07 \\
6.0 \%\end{array}$ & - & - & $\begin{array}{c}01 \\
(1.4 \%)\end{array}$ & - & $\begin{array}{c}17 \\
3.1 \%\end{array}$ \\
\hline Total of moments & 118 & 116 & 92 & 75 & 73 & 70 & 544 \\
\hline
\end{tabular}

Note: (n \%) - percentage calculated on the total number of moments recorded for each dimension.

Evaluation criterion were considered very satisfactory for mediate evaluation responses which identified at least one function six times and six dimensions (22 - 31.4\%); satisfactory, when at least four functions and four dimensions were identified (36-51.4\%), and unsatisfactory for those that identified one or more functions and less than four dimensions, and/or responses that despite identifying the correct functions did not correlate with the relevant dimensions, and/or blank or incorrect answers (12 - 17.1\%). All groups had very satisfactory and satisfactory results, in descending order: B $(90 \%-20) ; \mathrm{A}(80 \%-20)$ and C $(73.6 \%-10)$.

\section{DISCUSSION}

In general, the basic elements for effective communication are those that directly or indirectly respond to the goal of having harmony, respect and civility with yourself or with others, hence, the need to associate kind, gentle, clear and consistent content with local conditions (environment), internal (personal) and on the outside (for the other person) with the message. Also, to use non-verbal communication as a strategy to clarify the facts (messages) and facilitate their understanding through use of kinesics, paralanguage, proxemics and other nonverbal dimensions ${ }^{(7)}$.

Kinesics is the theory originated from studies on gestures and body movements, specifically decoding body signals. It is a system of perceiving body language, which is assigned a symbol to the main body movements, and thus can be transmitted and analyzed within a given social system ${ }^{(8-10)}$.

The assumptions of Kinesics is based on the fact that these movements and visible gestures contain meaning in the context for which they are presented; gestures that are not universal, but yet in which there is a synchronous communication process in which a person influences the other ${ }^{(9-10)}$.

Research carried out in post-graduation courses nurses on Kinesics has shown that nonverbal dimension is considered as a set of expressions and complex body movements able to express feelings, desires, emotions and externalize internal content ${ }^{(11)}$. This confirms the results found in this study, in which the participants recognized the Kinesic the expressions of feelings, complementation and verbal reinforcement contained in the scenes.

Facial expressions and how we talk can immediately communicate if the individual is or is not interested in what the other is saying or if your thoughts are on other facts, and if there are conditions that complement what is being said/shown/investigated. The facial expression of the health professional is so significant for the elderly as the elderly are for them, and when associated with tone of voice and rate of speech can express reasons or encourage interaction inhibitors ${ }^{(8-9,12)}$.

Among the facial expressions, smiling is the one expression able to reveal interest, kindness and sympathy, exerting a stimulating factor in the elderly who are hospitalized. However, one should avoid using it excessively, as it could likely be interpreted as a lack of seriousness or discrediting the report, causing insecurity. Expressions such as frowning may indicate that there is an effort to understand speech, or even translate attempted explanation of a fact. Monitoring or even becoming aware of performed facial expressions is a smart and effective strategy to enhance information and still transmit feelings towards the situation in context ${ }^{(12-13)}$.

It is known that body language can also be instinctive, taught or imitated, which is why culture is an important factor to be observed. Every movement or body position has distinct functions: adaptive, expressive and defensive, some conscious, others not; but if you know about them, there is the option to take the daily challenge to exercise them consciously in favor of interaction ${ }^{(8)}$.

The size of paralanguage is the result of the interaction of a number of improper linguistic variables, but referring to the vocal tract and involving: pitch, tone, intensity and pace of voice, pauses, type of vocalization (laughter, yawns, sighs, yells) and even vocal secretions ('Mmm,'“uhuh,' 'eh')(9).

Often, the voice can be classified as optional (intentional and voluntary) and not optional (resulting from genetics, social history, uncontrollable outcome of a situation). The intentional alteration of the voice may be an attempt to manipulate the listener. A strategy that should be used to validate such a condition is to pay attention to the message 
content and body and facial movements that are made, so you can check if it is an optional vocal trait or not ${ }^{(12)}$.

In general, when there is a negative message to be transmitted, it is common to change the tone of voice, to lower it even slightly, which may not always be reduced to manipulation, that is, the vocal traits should be evaluated with caution and validated with other non-verbal dimensions ${ }^{(12)}$.

The professional may not be able to become familiar with the vocal style of the elderly on the first contact, but should observe the general tone, cadence and other basic vocal traits in order to gain / recognize a pattern and check the changes later. Sticking to the vocal exaggerations is important, but the professional must be careful not to make early interpretations, especially when they do not know that patient well. Undoubtedly, the tone is a sensitive indicator of personality, mood and the environment it is in ${ }^{(12)}$.

Feelings are rarely only exposed by the tone of voice, usually they add to the type of chosen words and body language, thereby exposing emotion. If these facts do not match, something is wrong, there may be a contradiction between verbal and physical need and deserves further investigation. The most consistent patterns that are repeated and must be identified and interpreted more so as not to draw the wrong conclusions ${ }^{(9,12)}$.

Representation of one's will can be made by body signals, as they are the enabling means of expression and confirmation of desires, therefore abiding by the signals becomes essential in the care ${ }^{(8)}$.

The interest of the professional in the elderly can be demonstrated by a relaxed, empathic attitude, which enables an easier way to pay attention to their history, complaints or concerns. The elderly perceive the interest shown by paralanguage used by established eye contact, by approaching them and making contact. This set of actions will allow the elderly to relax and develop confidence in the professional, favoring adequate and effective interaction ${ }^{(14)}$.

A study developed with hospitalized elderly examined the perception of care identified for recovery in the attitude exercised by this health team in acts and gestures of attention, care, affection and in the form of aid or performing procedures, using a respectful touch, demonstrating safety and affection and also in attitudes that reveal patience to listen to and explain the activities, to look and act professional, polite, helpful, and to talk to them during hospitalization ${ }^{(6)}$.

It is relevant to mention that research of the elderly in a São Paulo urban area found that the perception of nonverbal communication was blocked, meaning it is not effective, by recognizing that the elderly had a health team - when they do not listen, or when they observed gestures of irritation or aggressiveness towards the professional that are inappropriate for them - it ends up providing constraints and leaving them with a feeling of dissatisfaction for the elderly ${ }^{(15)}$.

However, both the elderly and the professionals are part of each other's subjective states and exchange their intentions, ideas, desires and feelings. But with this interaction, there is a conformation of the power relationship, not given by the image of the other in itself, but by the place the other takes in the interaction ${ }^{(6)}$. The communication is presented in the cultural context as a complex phenomenon that combines the convergence and overlap of many activities in the hospital world. So that communication is effective in the health world, it requires the presence and mutual intention of communicating. This is because when relations are mutually established without appreciation of subordination or ordering, and in this way tend to gain a positive meaning and is favorable to recovery ${ }^{(16)}$.

Regarding Haptics, it should be noted that it is the dimension that involves having contact with human skin. The skin covers and protects the body, it is the most sensitive organ and the first means of communication with the world, through which the individual discovers and knows their environment, realizing their existing objectivity and subjectivity ${ }^{(9)}$.

Often, professionals also implicitly provide comments and feel they are authorized to touch the elderly when they need to do the procedures, but do not always consider it important to ask permission since they are helping the elderly ${ }^{(17)}$.

Professionals identified the scenes of the film shown in mediate evaluation of the training, which translated Haptics as a dimension used in the interaction. The results reinforce the opinion defended by the authors who claim that touch is so powerful it can be a determining factor in the outcome of diseases and disorders, which can lead to improvement or worsening. The appropriate touch in the context favors the elderly feeling safe and believing in their recovery, and it does matter. The use of touch and physical proximity can be an effective way to start the communication with the hospitalized elderly by providing them with the notion that they have human value ${ }^{(5,9)}$.

Therefore, it is recommended that professionals develop communication skills able to recognize the time, place, duration and intensity appropriate to the touching required. The consciousness of touch and of the questions that surround it are paramount to the success of the action, and translate attention and dedication in assisting the elderly ${ }^{(9)}$.

Environmental factors examined in light of non-verbal dimension involve a number of aspects that interfere in the binomial of the professional-elderly communication. A similar study using non-verbal training in gerontology developed with health professionals in 2009 allowed for sorting and analyzing seven distinct groups of these factors: noise and vibration; decor and space; brightness; colors and textures; thermal and ventilation; hygiene and safety, and visual signs ${ }^{(18)}$.

Environmental noise pollution has become abundant today, and intolerable. As a consequence, technological developments have potentially harmful noise levels in hospitals, and these are coming more from within than from the outside environment. The benefits of a calm and pleasant environment affect both those who are hospitalized as well as their professional team, as both suffer less psychological and physiological damage and experience less fatigue ${ }^{(19)}$.

It is pertinent to ratify that the Brazilian standard stipulates rules regarding the communication, and must be followed in order to collaborate in disseminating informa- 
tion, the location of areas and sectors, and also the flow and movement of people within the health services ${ }^{(20)}$.

It should be noted that communication covers visual communication with the use of text, pictures or international representation symbols; tactile with the use of raised characters and figures and sounds. All of them are a challenge to be met in health services, as they help in accessibility and inclusion of people, the elderly included ${ }^{(20)}$.

The legibility of visual information depends on the ambient light, contrast and color purity. The text and pictures, as well as the background of the signaling components must have a matte finish, avoiding the use of bright or highly reflective material. The texts containing guidelines, operating instructions of areas, objects or equipment, regulations and standards of conduct and use shall be of the type that uses a single positive complete sentence in the active voice and the order of actions, with emphasis on the correct way to perform a certain action ${ }^{(20)}$.

It is essential that the physical environment of the area that houses the elderly during hospitalization is appropriate for their functional limitations; that is being free of barriers and well lit in order to favor their communication, their families and caregivers ${ }^{(18,20)}$.

The participants in this study realized a real and effective way to offer appropriate assistance in scenes in the film, in relation to the presence of elements in the environment. They understood that environmental factors interfere in the well-being of the elderly; in their recovery and in their relationship with the professional who attends them. The current research results agree with previous research findings ${ }^{(18)}$.

Physical characteristics are another dimension of nonverbal communication that should be considered by health professionals when caring for the elderly, because they are attentive to detail and context. Both by what is done and how it is done constitutes a universe presented to the elderly that they observe and evaluate, and facilitate the interaction depending on the outcome. A professional image is characterized by an appearance which shows care with personal hygiene, and the presentation exposes the commitment and the responsibility inherent to the profession, and therefore choice of clothing and accessories are relevant aspects ${ }^{(21)}$.

Depending on the profession in health care, it is viewed and identified as a type of genre: for a healthy, young and cultured appearance, often with exclusive racial and discriminatory representations. Now this imagery will interfere with the ideal of the professional that the elderly want to be cared for and vice versa, in the way the elderly expect to be cared for. The result of this perception may hinder the establishment and maintenance of the bond, which is special and needs to exist in the hospital setting, thus interfering with the interaction ${ }^{(22)}$.

The answers of the participants of other training conducted with health professionals regarding the physical characteristics that could assist in communication could be categorized into: the professional taking care; professional exposing feelings / attitudes; professional realizing the health conditions of the elderly; and the professional recognizing the influence of prejudices ${ }^{(21)}$.
When these participants were asked how physical characteristics can aid in communication with the elderly, $68.4 \%$ reported that the health professional should: maintain good personal hygiene practices along with well-groomed hands and straight hair, wear clean clothes and in accordance with hospital guidelines, quiet shoes, discreet perfume and makeup, among others ${ }^{(21)}$.

Research conducted with caregivers of patients admitted to hospital stressed that recognizing the nurse from other professionals was through four actions: to present themselves at the time of care; wearing a uniform; wearing a name tag; and examining the patient. Thus, the fact that clothing does reveal professional identity can be inferred ${ }^{(23)}$.

One of the scenes recalled by participants in this study was the uniform and the name tag of the actors, which clearly revealed who each person was, and realizing that helps the elderly in identifying professionals, confirming the previous findings cited.

Proxemics is the science that studies the relationship of man with his personal and territorial space. Normally, when the individual is invaded, this triggers the production of behaviors, often nonverbal, indicating discomfort with the situation. Anxiety, avoidance, escape, restlessness and / or adaptation are reactions which may occur, however, they are closely related to individual needs, previous experiences and culture. Each culture has particular ways of expressing feelings, emotions and of using the distance of space itself. The environmental provision must be considered as well as the amount of people present in a given location ${ }^{(8,9,24)}$.

An exploratory study of hospitalized elderly in São Paulo hospital identified the unpleasant situations considered as an invasion of territorial space, which were those linked to disrespect and to change the physical space without authorization; those concerning the invasion of personal space were related to exposure of intimate parts during the performance of technical procedures. Pleasant situations, despite intrusion, were those in which affectionate touches occurred ${ }^{(8,25)}$.

It may be added that communication is an act that is done in time and space through dimensions that go beyond the spoken word. The meaning of communication is the relationship of the need and desire to be with each other, which gives impulse and a resignificance to life $^{(16)}$. In terms of emotions, verbal and non-verbal are nothing but the look/make of the world under the impulse of interest and empathy inherent to accomplish a task which includes the compulsory (real need) and the desired governed by pleasure standing together and making a difference ${ }^{(25)}$.

They recognize that communication is a defined process and marked in interactions in which they share ideas, thoughts and desires, and can take on a valuable resource in helping the relationship ${ }^{(25-26)}$.

Older people feel embarrassed to ask or answer questions, feel ashamed of body exposure, suffer from neglected privacy and are also sad, afraid and suspicious of the hospital world. For them, this is because it is common that technical language which is difficult to understand is used at a level higher than its real need, and so as not to allow listening to their answer since the professional's time is short ${ }^{(6)}$. 
In the context of showing emotions, it is stressed that each person builds their network of personal beliefs about life, death, love, work, and even intra and inter-personal, which interferes with the expression of the same ${ }^{(25)}$.

It is common for individual reactions to be determined more by the internal interpretation of the events themselves. The professional who struggles for quality work needs to develop an external and circumstantial look, accept their limitations, recognize their biases and understand that often it is in the process of defending their beliefs and not being open to evolve, mature or develop affections. Communication needs to be addressed and understood by the quality of the relationship, the experienced, and experimented, and this is possible when there is belief in what another feels, and are open to new concepts and accepting change ${ }^{(5)}$.

The lack of training for teams that take care of the elderly and the weakness of the existing political structure in countries hinder the development of competence to care for the elderly in the various levels of care. The training of human resources in the area of gerontology is linked to the understanding of the aging process and its biological, physical, social, economic and psychological repercussions; the value of the required multidisciplinary work; the disruption of the design paradigm of health and illness; the enhancement of communication among professionals, managers, seniors and family, and also the conscientious use of resources and communication dimensions. All these points will help to maintain the quality of the work with the elderly and their consequent satisfaction.

\section{CONCLUSION}

The content assimilation index contained in the program immediately after the application (90 days after the last meeting) was very satisfactory and satisfactory in $82.9 \%$. The results per group in descending order were: B (90.0\%), A (80.0\%) and C (73.3\%), which confirms the efficiency of the proposed program.

Because the participants achieved satisfactorily assimilating the proposed program and the composition and content of the responses, it can be said that the second hypothesis of this research was also confirmed. The replication of the program proved to be relevant and updated the setting of hospital services, making it efficient and applicable to health professionals.

It is argued here that skills are mediated by knowledge, attitude, manner to do things by the individual and the collective. The fact that the participants have satisfactorily described the nonverbal functions and dimensions alone does not guarantee the actual presence of enough instrumental ability to change the work environment and / or relationship with the elderly. The training is an attempt to mobilize and enable health professionals who care for elderly.

\section{RESUMO}

Objetivo: Replicar o programa de capacitação em comunicação não verbal baseado no referencial teórico da comunicação interpessoal; da codificação não verbal, valorizando os aspectos próprios do envelhecimento na perspectiva do envelhecimento ativo, verificando sua pertinência na atualidade por meio do índice de assimilação do conteúdo após 90 dias (mediato) de sua aplicação. Método: Estudo de campo descritivo e exploratório desenvolvido em três hospitais de administração direta do estado de São Paulo que atendem exclusivamente clientes do Sistema Único de Saúde (SUS). A capacitação teve duração de 12 horas, dividida em três encontros, aplicada em 102 profissionais de saúde. Resultados: Revelaram índice de assimilação mediato do conteúdo muito satisfatório e satisfatório em 82,9\%. Conclusão: A replicação do programa revelou-se pertinente e atualizada ao cenário dos serviços hospitalares, mantendo-se eficiente aos profissionais de saúde.

\section{DESCRITORES}

Comunicação não Verbal; Idoso; Envelhecimento; Educação em Saúde; Enfermagem Geriátrica.

\section{RESUMEN}

Objetivo: Replicar el programa de capacitación en comunicación no verbal basado en el marco de referencia teórico de la comunicación interpersonal; la codificación no verbal, valorando los aspectos propios del envejecimiento en la perspectiva del envejecimiento activo, verificando su pertinencia en la actualidad por medio del índice de asimilación del contenido luego de 90 días (mediato) de su aplicación. Método: Estudio de campo descriptivo y exploratorio desarrollado en tres hospitales de administración directa del Estado de São Paulo que atienden exclusivamente a los clientes del Sistema Único de Salud (SUS). La capacitación tuvo duración de 12 horas, dividida en tres encuentros, aplicada a 102 profesionales de salud. Resultados: E1 92,9\% revelaron índice de asimilación mediato del contenido muy satisfactorio y satisfactorio. Conclusión: La replicación del programa se mostró pertinente y actualizada al escenario de los servicios hospitalarios, manteniéndose eficiente con respecto a los profesionales

\section{DESCRIPTORES}

Comunicación no Verbal; Anciano; Envejecimiento; Educacíon en Salud; Enfermería Geriátrica.

\section{REFERENCES}

1. Brasil. Secretaria de Assuntos Estratégicos; Instituto de Pesquisa Econômica Aplicada (IPEA). PNAD 2009 - primeiras análises: tendências demográficas. Brasília: IPEA; 2010.

2. São Paulo. Decreto n. 58047, de 15 de maio de 2012. Institui o Programa Estadual São Paulo Amigo do Idoso e o Selo Amigo do Idoso e dá providências e correlatos. Diário Oficial do Estado de São Paulo, São Paulo, 16 maio 2012. Seção I, p.1. 
3. World Health Organization (WHO). Envelhecimento ativo: uma política de saúde. Brasília: Organização Pan-Americana da Saúde; 2005.

4. Prochet TC, Silva MJP. Estratégias que colaboram na independência fisica e autonomia do idoso hospitalizado. Rev RENE. 2011;12(04):67883.

5. Prochet TC, Silva MJP, Ferreira DM, Evangelista VC. Affection in elderly care from the nurses' perspective. Rev Esc Enferm USP. 2012;46(1):96-102.

6. Prochet TC, Ruiz T, Corrêa I. A humanização do atendimento ao idoso: o que o idoso hospitalizado sente, percebe e deseja? Nursing (São Paulo). 2006;9(94):713-8.

7. Lamela D, Bastos A. Comunicação entre os profissionais de saúde e o idoso: uma revisão da investigação. Psicol Soc. 2012;24(3):684-90.

8. Prochet TC, Silva MJP. Proxemics: situations in which hospitalized elders recognize intrusion into their personal and territorial space. Texto Contexto Enferm. 2008;17(2):321-6.

9. Silva MJP. Comunicação tem remédio. $8^{\text {a }}$ ed. São Paulo: Loyola; 2012.

10. Elkman P. Linguagem das emoções. São Paulo: Leya; 2010.

11. Silva LMG, Brasil VV, Guimaraes HCQCP, Savonitti BHRA, Silva MJP. Comunicação não verbal: reflexões acerca da linguagem corporal. Rev Lat Am Enfermagem. 2000;8(4):52-8.

12. Dimitrius J, Mazzarella WP. Decifrar pessoas: como entender e prever o comportamento humano. São Paulo: Elsevier; 2009.

13. Leite AJM, Caprara A, Coelho Filho JM. Habilidades de comunicação com pacientes e família. São Paulo: Sarvier; 2007.

14. Braga CS. Linguagens não verbais: lente semiótica para a observação do corpo no baile. Moringa. 2013;4(2):11-23.

15. Almeida RT, Closak SI. Communication between the elderly person and the Family Health Team: is there integrality? Rev Lat Am Enfermagem. 2013; 21(4):884-90.

16. Peruzzolo AC. A comunicação como encontro. São Paulo: EDUSC; 2006.

17. Bettinelli LA, Pomatti DM, Brock J. Invasão da privacidade em pacientes de UTI: percepções de profissionais. Bioethikos; 2010;4(1):44-50.

18. Prochet TC, Silva MJP. Environmental factors as supportive components in communication and care for hospitalized elderly. Rev Bras Enferm. 2012; 65(3):488-94.

19. Costa GL, Lacerda AB. Marques ABM. Ruído no contexto hospitalar: impacto na saúde dos profissionais de Enfermagem. Rev CEFAC. 2013;15(3):643-52.

20. Associação Brasileira de Normas Técnicas. ABNT NBR 9050. Acessibilidade a edificações, mobiliário, espaços e equipamentos urbanos. Rio de Janeiro: ABNT; 2004.

21. Schimidt TCG, Silva MJP. Influência das características físicas humanas na comunicação do profissional da saúde com o idoso. Rev Min Enferm. 2013;17(3):510-6.

22. Campos PFS, Oguisso T. Escola de Enfermagem da Universidade de São Paulo e a reconfiguração da identidade profissional da Enfermagem Brasileira. Rev Bras Enferm. 2008;61(6):892-8.

23. Sugano AS, Sigaud CHS, Rezende MA. A enfermeira e a equipe de enfermagem: segundo mães acompanhantes. Rev Latino Am Enfermagem. 2003;11(5):601-7.

24. Hall ET. A dimensão oculta. São Paulo: Martins; 2005.

25. Lenardt MH, Hammerschmidt KSA, Pivaro ABR, Borghi ACS. The elderly and their restraints in the event of surgical hospitalization. Texto Contexto Enferm. 2007;16(4):737-49.

26. Schimidt TCG, Silva MJP. An approach to touching while providing high-quality affective health care to hospitalized elderly patients. Rev Esc Enferm USP. 2013;47(2):426-32. 